\title{
Influence of Game Design and Playability Toward Continuance Intention Using TAM Framework
}

\author{
Rocky Tarsisius Pantouw ${ }^{1}$ and Daniel Tumpal H Aruan ${ }^{1}$
}

\begin{abstract}
As the growth of game industry, only few Studies in mobile games, and also focused on pre-adopting while ignoring post adoption behaviors. One intrinsic factor considered affecting gameplay is enjoyment. Some research has already conducted to understand what is enjoyment driver. Enjoyment is an external factor that influenced perceived usefulness. where perceived of usefulness is variable proposed in TAM. This study aims to examine impact the game design attribute that fit and influence enjoyment while play game and as a motive of continuance mobile game use in MOBA genre. This research adopts game design attributes of challenge, variety, novelty, design aesthetics, social interaction, playability attributes consist of perceived of use and interactivity. Structural Equation Modeling (SEM) is used for data analysis. The model is tested with 206 actual users. The findings put Novelty, design aesthetic and interactivity under observed. This research concluded that continual mobile game use is strongly driven by perceived of usefulness. The implications are discussed in the paper.
\end{abstract}

Keywords-Mobile Games, MOBA, Enjoyment, Continued Use, TAM.

\section{INTRODUCTION}

Nowadays, A mobile game is an application that is played on a small device so that it is easy to carry and play anywhere. Mobile games are usually more casual games which are usually simple arcade games [1]. But with the development of device capabilities, many game developers began adopting games that were originally on a Private computer (PC) and began to be customized for smaller devices such as cellphones and tablets.

In the context of a game, there are many genres that have been developed, one of which is the Multiplayer Online Battle Arena (MOBA) genre. This genre is a derivative of the Real-time Strategy (RTS) game. The concept of this game in one game consists of 2 opposing teams, usually, each team consists of 5 people. Each player has their own role to play, and work together to win the game by destroying the main building of the enemy. This genre starts to Adoption into mobile games and is widely played by many people. Recorded there are several titles of mobile games that are busy playing such as Arena of Valor (AOV), Mobile Legend (ML), and Vainglory (VG). based on research data, there are more than 10 million players for

\footnotetext{
${ }^{1}$ Rocky Tarsisius Pantouw and Daniel Tumpal $\mathrm{H}$ Aruan with University of Indonesia, Jakarta, 10430, Indonesia. E-mail: pantouwrocky@gmail.com; dtumpal@yahoo.com.
}

AOV and VG, while for ML users download more than 100 million.

Today Mobile Online Games has become popular in the world. Globally the games industry has increased every year. Especially in the type of mobile games were in 2017 mobile games accounted for $46 \%$ of the total income from the gaming industry with total revenue of $\$ 121.7$ billion, this percentage increased by $6 \%$ for mobile games, and revenue growth reached $14 \%$ compared to 2016. This increase is also predicted until 2021 [2].

The development of a game was also followed by the development of the community so that a competition was held to test abilities and also the promotion of the game. The term is now better known as E-Sport. The classification of e-Sport itself in sports still attracts a lot of debate, this is also influenced by the definition of actual sport [3]. There are two points of views related to the definition of sports, a sport is activities that pay attention to health while on the other hand, consider the aspects of management and also sectors that might be looked at by the company [3].

E-Sport or gaming in Indonesia officially became a sports branch marked by the establishment of e-Sport associations (IeSPA) in 2014 [4]. the rapid development of eSport brought the gaming industry in Indonesia to 16th place in 2017 [4]. However, video games must have a regulatory structure, organization, and competition to be considered as sports [5], so not all games can be included in e-Sport.

Several researches on games have started to be done, starting from identifying attributes of a game, to performing a gamification process for the needs of a campaign or promotion. Some researchers focus on understanding continuance intention to play games and what causes them [1]. In a study conducted by [1] focusing on finding out what makes continuance use become Enjoyable. They design a model and divide it into two dimensions, namely game design, and playability which is thought to affect enjoyment. The rest of this study was conducted on several types of games especially with arcade genres such as candy crush and angry bird. But to understand continuance use in other genres requires further research because of differences in terms of mechanical, design, and aesthetic. In response to this matter, there is a need for research related to the games themselves, especially the mobile games that contribute to income in the gaming industry. This is related to how a game should 
be made and what attributes make a game not abandoned by the player.

Previous study mentioned that various communication channels (printed materials, special event/campaign, etc) did not provide enough motivation and were less effective in encouraging behavior [6]. A new concept communication channels has been developed to and its called gamification, this concept is defined by [7] as "the use of game design elements in non-game contexts to improve user experience and user engagement". This provide new opportunity to developed game for communication channel for marketing purposes, or other purposes. Some research also prove that gamification is an effective communication channel for conservation energysaving campaign [6] and also need to test in other filed especially marketing.

In this study, researchers conducted replication and modification of the research conducted by [1], by using Technology Acceptance Model (TAM) and focusing on enjoyment as a driver of Perceived of usefulness, related to what made continuance of use enjoyable in a game. This study uses two dimensions of game attributes used in the study, namely game design, and playability. The modification made by researchers is to add attributes to the dimensions of the game design, namely social interactions that researchers take from [8].

This study would focus on enjoyment, related to what made continuance of use enjoyable in a game. The genre game of this research is MOBA and the title of the game for this research is Arena of Valor, Mobile Legend, and Vainglory.

\section{LITERATURE REVIEW}

\section{A. Game Design}

\section{1) Challenge}

Challenge defines as sense that one 's capabilities are being stretched. Challenge is divided into 2 namely positive and negative. Negative challenges are usually associated with problems that can interfere with games such as slow internet speeds, while positive challenges such as sports. Positive challenges are often found as important predictors in flow and user enjoyment in a variety of settings, especially in hedonic environments [8] Challenge is a relevant component of game design in a content game

\section{H1: Challenge will influence Perceived Enjoyment}

\section{2) Variety and novelty}

Merikivi, Tuunainen, \& Nguyen (2017) explain Variety leads to the extent to which a person feels variations in conditions in the game, while novels lead to the extent to which a game regenerates to make new features. Variety and novelty cannot be separated from a game [1], this is done so that players do not feel bored playing games that have no variation on the content.
Variety and Novelty cannot be separated. Giving new features or new game elements can provoke the curiosity of users to play a game, and so that users do not feel bored. The more often players/users play a game, the more familiar they are with the content of the game, which can reduce stimulation of content [1].

H2: Variety will influence Perceived Enjoyment H3: Novelty will influence Perceived Enjoyment

\section{3) Design Aesthetics}

Design Aesthetics is a balance, emotional appeal, or aesthetic in mobile games [1]. Design Aesthetic has been examined to have an impact on enjoyment, some studies have found that mobile games with aesthetic design receive positive evaluations from users, aesthetic design also shows a positive effect on the perception of mobile system users [1].

H4: Design Aesthetic will influence Perceived Enjoyment

4) Social Interaction

Interaction is defined as 2 communicating objects and influencing each other, interactions are considered to be one of the important aspects in playing computer games [9]. In term of social, a player communicating with others to develop relationship or cooperating in game. Social interaction in games can increase user flow experience [8]. In MOBA games interaction with other people is the key to playing the game.

\section{H5: Social Interaction will influence Perceived} Enjoyment

\section{B. Playability}

Playability as how players interact with games, where gameplay focuses on the mechanics of a game and is related to the player's playing experience [10].

\section{Playability attribute}

\section{5) Interactivity}

Interactivity leads to the performance of the game response that is felt by the user. when the game response is fast, it can facilitate active and direct interaction within the game [1]. Mobile games are usually played in a casual, short term. Game response to player actions can affect gameplay experience [1].

\section{H9: Interaction will influence Perceived Enjoyment}

\section{6) Enjoyment}

Several previous studies explained that enjoyment has a direct influence on continue intention in mobile gaming. Enjoyment is defined as the extent to which activities using new technology are felt pleasant, besides the consequences of performance, Enjoyment is a direct trigger for continuance intention in mobile games [1]. The relationship between enjoyment and use continuance can be said as straight forward, and also shows that enjoyment can be a strong predictor for several outcome variables such as use continuance and purchase intention, in several 
studies it is shown that there is a positive relationship between enjoyment and continuous use in various environments for example: on online games, web 2.0 and facebook games [11]. The research results from [1] explain that enjoyment has a direct influence on continued mobile gaming. In TAM, there are 2 important external factors, perceived informativeness and perceived enjoyment [12].

H10: Perceived enjoyment will influence Continuance Intention

H11: Perceived enjoyment will influence Perceived Usefulness

\section{Technology of acceptance model (TAM)}

The theory of acceptance model (TAM) offered by Davis et al (1989) is widely accepted as a model for testing user attitudes, satisfaction and behavioral intention in using new systems or technologies. This model predicts factors that lead to user acceptance based on 2 factors, perceived usefulness, and ease of use [13].

7) Perceived ease of use (PEOU)

Perceived of Ease of Use is defined as the extent to which a person when using a particular system does not require more or easier effort. This has been suggested if a system that is easy to use can increase user enjoyment [1]. Perceived ease of use is confirmed to be a determinant of enjoyment [1]. Technology of Acceptance Model (TAM) offered by Davis et al (1989) is widely accepted as a model for testing user attitudes, satisfaction, and behavioral intention in using new systems or technologies. TAM uses 2 factors, namely perceived of usefulness and ease of use [13].

H6: Perceived ease of use will influence Perceived Enjoyment

H7: Perceived ease of use will influence Perceived Usefulness

H8: Perceived ease of use will influence Continuance Intention

8) Perceived usefulness

Perceived of usefulness is the extent to which a person considers a technology or system able to improve its performance in a specific activity, this construct builds different studies based on motivation, expectations and information systems [14]. In Davis et al's (1989) TAM model, perceived ease of use and perceived usefulness are connected with attitude and behavioral intention using innovation.

H12: Perceived usefulness will influence continuance intention

\section{E. Continuance Intention}

Continuance intention leads to post-adoption behavior, post-adoption itself refers to behavior after the first use, including continuance, routinization, infusion, adaptation, and assimilation [9].

\section{METHOD}

This study uses a framework from TAM and focuses on enjoyment which is a driver of the perceived of usefulness. This research model is an adaptation of the research of [1]. The researcher has also modified the model by adding social interaction in game design element, because this element is really useful in MOBA game to communicate with the team and make a strategy. The researcher also added TAM framework because this theory can predict factor that leads into behavioral intention, in this context continuance intention to play MOBA game. Whereas continuance intention is a post-adoption behavior after the user had evaluated the game.

The study collecting data from questionnaires that were distributed by online. The survey consists of 4 sections, first sections is a respondent identity, second is MOBA verification to make sure that the respondent has already been playing MOBA mobile game, the third section is Game selection this section to identify what is game that played by respondent, the last section is the evaluation of

the game by respondent. Each factor is measured using Likert scale ranging 1 to 6 , where 1 indicates that the factor is very unimportant/strongly disagree and 6 indicates that the factor is very important/ strongly agree. The researcher is also giving lottery to encourage respondent to fill up the questionaries. Before the main test the researcher has been conducted pretest to measure validity and reliability indicator, to check validity and reliability are using SPSS and the overall result was all indicators are validity and reliable, and can be used for the main test for the detail result see Appendix C.

\section{DATA ANALYSIS}

In total there were 285 visitors in this survey, 206 response were received, yielding response rate (72\%), 79 response that is partially complete excluded in data analysis, and also the researcher excluded the extreme data with an indicator of extreme data is 11111, or 66666 from data analysis. Majority of this sample are Male (92\%), almost half (46\%) of all respondent are between 20-24 years. And with two thirds (66\%) of all respondent intensity playing game is every day. Overall the demographics respondent characteristics in this research are male with age are between 20-24 years with intensity playing game is every day, for more detailed information about demographic see Appendix B.

For analysis, this study was using Structural Equation Modeling (SEM) to test the model. For validity, the test is done by Confirmatory Factor Analysis (CFA). CFA can confirm the number of constructs and indicators as expected on the basis of theory. This test requirement is considered validity and reliability or this research can continue, and the indicator is using Average Variance Extracted (AVE), and Composite Reliability (CR). The result of CFA is all the variable were meet the convergent 
validity, and for discriminant validity overall variable met the requirement (see Table 2). Also for fitness indices
$($ RMSEA $=0.07 ;$ TLI $=0.911 ;$ CFI $=0.920 \mathrm{cmin} / \mathrm{df}=$ 1.993) signaled a good model fit.

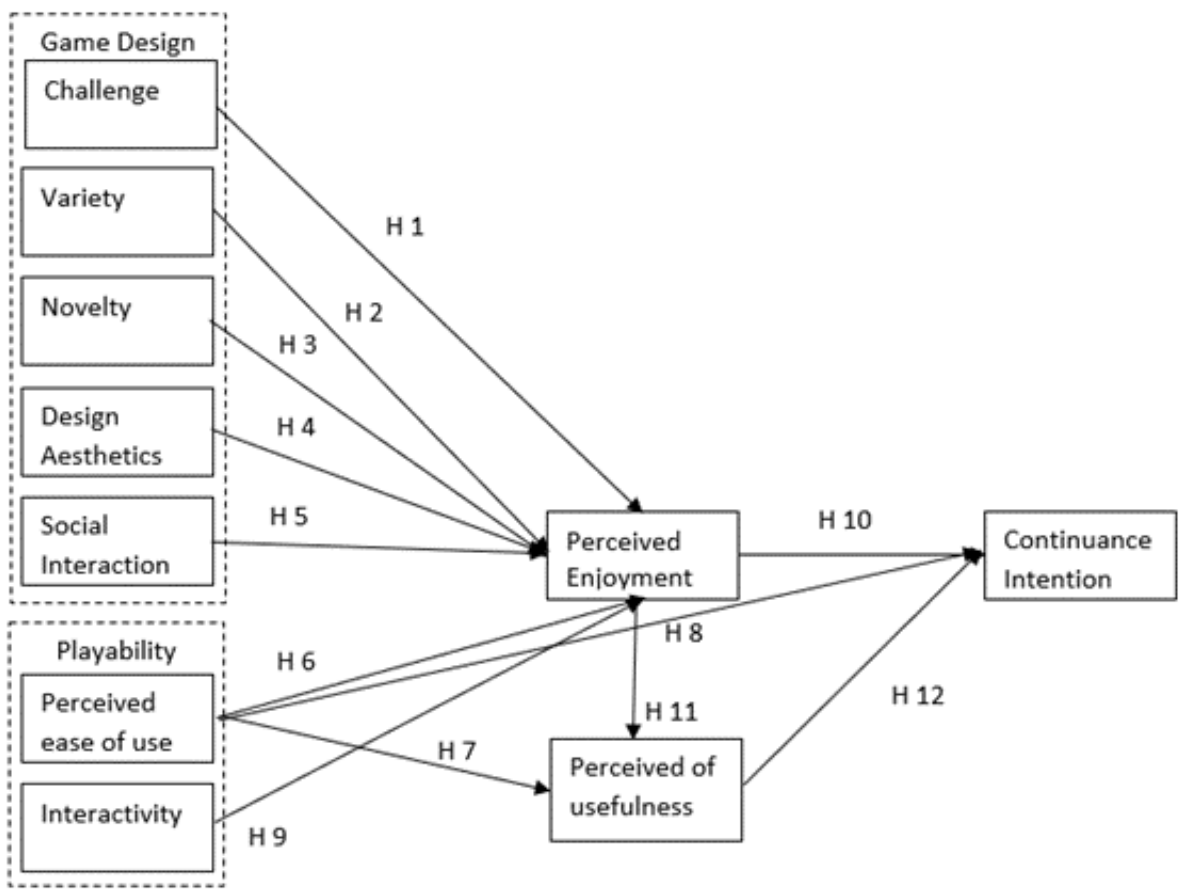

Figure 1. Model and Hypotheses

TABLE 2.

CONVERGENT VALIDITY AND DISCRIMINANT VALIDITY

\begin{tabular}{|c|c|c|c|c|c|c|c|c|c|c|c|c|c|c|}
\hline & CR & AVE & MSV & $\operatorname{MaxR}(\mathrm{H})$ & ENJOYI & CHALLE & VARIET & NOVEL & D.AEST & S.INTER & P.EOU & INTERA/P & & C.INTEN \\
\hline ENJOYMENT & 0.941 & 0.843 & 0.634 & 0.957 & 0.918 & & & & & & & & & \\
\hline CHALLENGE & 0.940 & 0.759 & 0.646 & 0.946 & 0.732 & 0.871 & & & & & & & & \\
\hline VARIETY & 0.897 & 0.745 & 0.746 & 0.919 & 0.712 & 0.797 & 0.863 & & & & & & & \\
\hline NOVELTY & 0.878 & 0.706 & 0.780 & 0.883 & 0.783 & 0.789 & 0.783 & 0.840 & & & & & & \\
\hline D.AESTHETIC & 0.963 & 0.838 & 0.774 & 0.971 & 0.796 & 0.797 & 0.864 & 0.880 & 0.915 & & & & & \\
\hline S.INTERACTION & 0.875 & 0.637 & 0.440 & 0.887 & 0.663 & 0.642 & 0.531 & 0.608 & 0.615 & 0.798 & & & & \\
\hline P.EOU & 0.774 & 0.536 & 0.045 & 0.804 & -0.017 & -0.211 & -0.162 & -0.177 & -0.165 & 0.086 & 0.732 & & & \\
\hline INTERACTION & 0.738 & 0.589 & 0.426 & 0.787 & 0.653 & 0.447 & 0.430 & 0.619 & 0.545 & 0.440 & 0.023 & 0.768 & & \\
\hline P.U & 0.923 & 0.801 & 0.780 & 0.934 & 0.774 & 0.804 & 0.685 & 0.883 & 0.794 & 0.625 & -0.088 & 0.612 & 0.895 & \\
\hline C.INTENTION & 0.965 & 0.873 & 0.743 & 0.973 & 0.769 & 0.781 & 0.685 & 0.816 & 0.785 & 0.594 & -0.120 & 0.467 & 0.862 & 0.934 \\
\hline
\end{tabular}

\section{A. Result}

The result of the analysis is shown in figure 2 . The model fit of Structural model was good fit (RMSEA = $0.076 ;$ TLI $=0.910 ;$ CFI $=0.920 \mathrm{cmin} / \mathrm{df}=2.170)$. the result of this model is Enjoyment and Perceived of usefulness are significant influenced to Continuance Intention, whereas Perceived of Usefulness is a strong driver (0.60) and explains $79 \%$ of the variance of continuance intention. Enjoyment is a strong driver of Perceived of Usefulness and could explain $83 \%$ variance of perceived of usefulness. the selected driver for Enjoyment determine $83 \%$ of Enjoyment. Nine of the twelve hypotheses are statistically significant. The hypotheses of challenge (H1), variety $(\mathrm{H} 2)$, and perceived ease of use (H8) were rejected.

\section{DISCUSSION}

The aim of this study was to examine whether intentions to continue using mobile games track enjoyment, and to identify the drivers of enjoyment, and also to determine acceptance of game based on TAM framework.

First finding of this research is the empirical result confirm that the game design element were related and became attribute sponsor of enjoyment. On the other attribute is perceived of usefulness is a main driver for continuance intention, perceived enjoyment and perceived of usefulness are finding could explained continuance intention $79 \%$. As a whole the research find beside the elements of the game other factor that will influence continuance intention is a perceived of usefulness of the game and proof main driver as continuance intention, but 
this study didn't focus for perceived of usefulness driver, so need to consider external factor that influence perceived of usefulness other than enjoyment. Enjoyment also be strong driver for perceived of usefulness as the previous research mentioned [12].

Second when focused on the element related elements game design and playability that influence enjoyment novelty is a strong driver, novelty is a ability to divide the artifact related attribute into those and controlled by game designer [1]. As this study aim for this research, two dimension were used for this research could explain variance enjoyment $83 \%$, there is need to concentrate playability dimension for future enjoyment.

Third, Novelty (0.35) and Design Aesthetics (0.25) were strong driver as the previous research mentioned [1], player most enjoyed novelty and design aesthetics in MOBA context, not challenge as researcher assume. Showing that in this research Challenge is not significant influenced the enjoyment this because when player facing difficult game with another people that might have higher skill from them it make them didn't enjoy the game like should. The component of flow theory as the researcher adapt from [8], is consider important attribute for game, especially in MOBA genre. To justify this MOBA genre is a team group and need communicate with other to build up strategy. The fact about novelty and Design Aesthetic were main driver of enjoyment because people like new thing from a game, and also the graphic that was presenting in game is also consider to make people enjoy playing game. Another fact were found is Perceived ease of use is negatively influence perceived of usefulness in MOBA context. The justify about it is MOBA is known as complex game where in most everygame of moba the character control was complicated and have unique mechanic. When player see MOBA game is easy to control they might be enjoyed but player didn't see those game usefull, is like another pass time game and did not consider that game as MOBA because of simplicity.

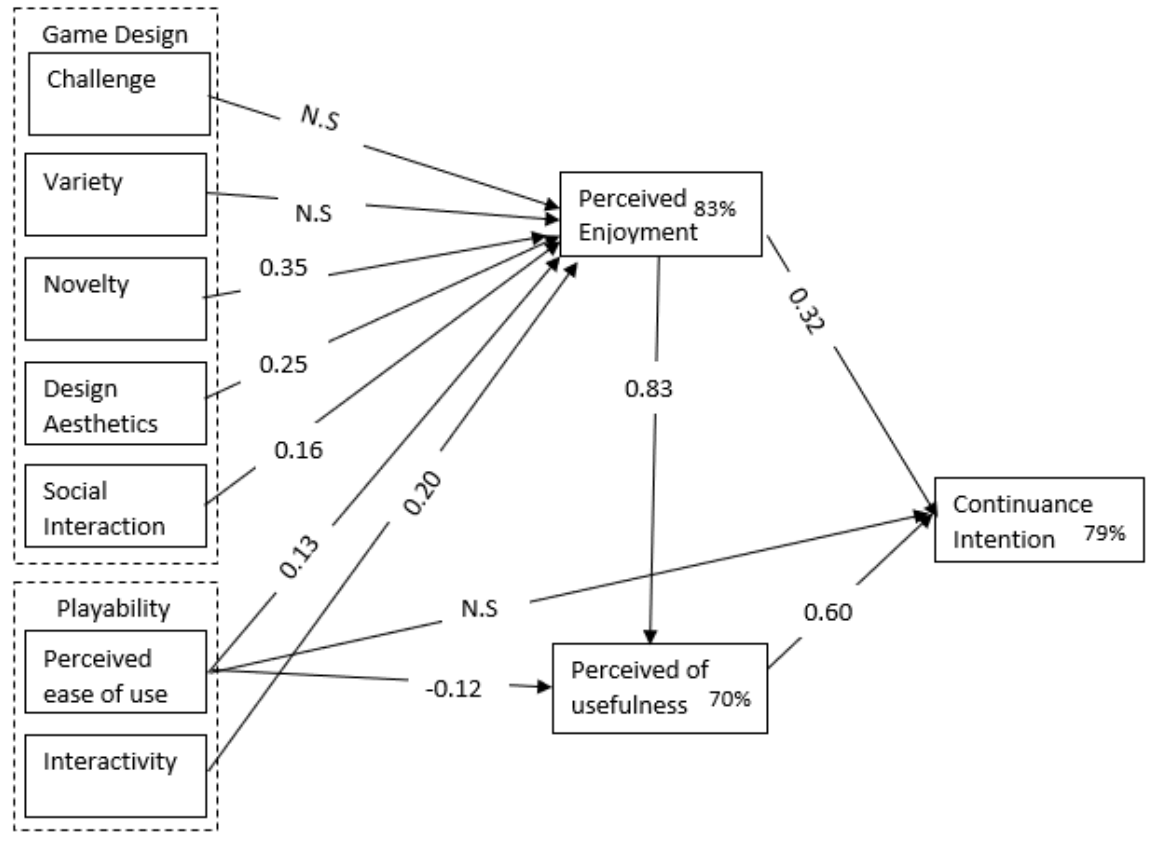

Figure 2. SEM Result

\section{A. Theoretical Implication}

From theorical, this research contributes several contributions. First, the finding that enjoyment and perceived of usefulness were a direct and effective influence in continuance intention. Perceived of usefulness is main driver of continuance intention, player would think that game is usefull when the game itself could help them with their activity, some research mention about mobile game is used for pass time, but now playing game can help player to achieve other goals other than pass time such as gain money through streaming platform, competitive to winning prize, etc. This study also confirms that enjoyment is a motive for continuance intention, this can be realized when a people engage in an activity/game. Evaluation for enjoyment could be negatively affected by subordinate responses or external factor other than game design and playability attribute itself, such as other player experience, and make a gap in skill while playing, that could make continuance intention enhanced or dismished [1]. In this case it would be difficult to predict continuance intention playing mobile game, whether they continued play game because they enjoy those game or other motives. 
Second, this study provides game design and playability attributes whereas that collaboration of those two dimensions that researcher adapt from [1] were proving that their model is could be used to examine enjoyment of playing game from the game design and playability attributes, the researcher also add social interaction in game design to answer the limitation in previous research, and the result is social interaction is one determinant should be considered to game design and affected the enjoyment.

Third, this study found that challenge had not significant, this against the previous hypothesis that researcher adapt, in MOBA game the player will face other players with different experience, the different experience could make gap in skill when playing game and in the context MOBA genre this could make this game unbalance, so balance tiering could make the game enjoyment. Player didn't enjoy when fighting people with different skill in game and the result is losing/winning in the game, so it looks different skill it's already solved by tiering so challenge in MOBA is not significantly affected. This study also found that perceived is ease of use is negatively influenced perceived of usefulness, in MOBA context when the game is provided with easy control it will lose their identity as MOBA, MOBA is known as complicated genre when the control is simple for example auto, or tapping game it will make player will see that game is not MOBA and didn't see them usefull.

Finally, the result of this research confirmed the role of novelty, design aesthetic, and interactivity as a determinant of perceived enjoyment. As most users play mobile games with MOBA genre graphic presented in device should consider whether high definition and smootheness in gameplay, this does not include negative challenge like device is using by player. In MOBA smootheness of graphic and controlling is an important factor because when playing MOBA it require smoothness of animation and also responsive from the tool to play the game because when playing MOBA game every missed movement could affect the game and mostly could trigger negative impact in game, this also prove that interaction is significantly influenced the enjoyment. Novelty is important in every game nowdays when looking game with every genre it will provide the same gameplay with some modification either story, character, gacha system, etc. so when people seeing the game is new concept it would make them interesting to try, but furthermore a development about the game is crucial and adding new content it should be considered important, because people will easily bored when content is not variative and new.

\section{B. Practical Implication}

This research mainly implication for game developers in how to create an enjoyable game experience and make people continued use of mobile games, and furthermore this framework could be used for alternative of communication channel.
Nowdays there are so many mobile games, with many genre and title and if comparing the game each other they have some similarity in gameplay, the reason might be they developed using the same engine. In MOBA context almost everygame in market using same engine to control, but the graphics and feature development is a work for game developers. Providing new features and it didn't copy from other game it will make the game more interesting and easily to use. Every game in market rightnow is freemium where people could access the game but if want faster progress they must spend money on it, this will affect continued intention if developer put a higher price to buy new heroes or avatar, or make people spend time to get it. So it should be considered when the developer wants to introduce new avatar and features, a guide will be good to help player to use new features. Adding to much features and affect gameplay will affect the enjoyment of playing game.

The development of gameplay also play important aspect in MOBA genre adapting the game it takes time so when the developer decides to change the gameplay it should consider it is acceptable and adaptable by player. Make easier controller in MOBA genre would make player didn't see that game as MOBA because MOBA is known as complicated control to handle and need training to mastering every character in it. The response of game they developed is also a critical thing to developed when player found the game didn't respond like what player wants it will negatively affect enjoyment in game. And the other thing beside the internal of game the developer should think about how they communicate their game and build up communities to keep the feedback from it and also make people didn't leave the game by keeping the game uptodate and support event in communities.

\section{Limitation and Future Research}

This study also makes several contributions to understanding of enjoyment and also what makes continuance enjoyment in mobile games. This study already includes social attributes like in previous research mention to add social attributes to measure enjoyment. This research was adapting indicator from [1] for playability indicator should be review and adjusting so it will suitable with genre in game and should not take as generally.

Our data was collected with cross sectional method more specific is a single point to measure continuance intention. Longitudinal studies with data collected at different points of time would add another insight into enjoyment. as we know when make video game it and sell it to market it would be accessed by people not only in one country but more like region or larger depend on server, so it would be provide more insight if the sample was across country because they might be have different point of view about element in game, and This study also only collect data from questionnaire so interview with an expert in game developer and player will provide more information to 
analyse about how to make game and make the game enjoyable.

Motives of playing game in every user is different they have other reason each other, this study already proof using TAM framework that perceived of usefulness of game is a strong driver of continuance intention, but this study did not provide enough survey about extrinsic benefits when people playing a game especially MOBA genre, the future research should investigate more detail about what extrinsic benefits will people get when playing game. Researcher also assumes that every genre of game that every people play have different benefit for people. Furthermore, this framework could be tested for gamification where it's new model have been developed for comunication channel, and need to be tested in various genre and for gamification if needed.

\section{CONCLUSION}

This study examined the relationship between enjoyment, perceived of usefulness and continuance intention, but mainly what makes mobile games enjoyable in MOBA genre. the findings confirm enjoyment has a direct effect continued intenions, and perceived of usefulness is a strong driver of continuance intention, and should be added other external factor that could be influenced perceived of usefulness other than enjoyment. This study also shows enjoyment in a mobile game context depends on two dimension game design, and playability attributes. Novelty, design aesthetic, and interactivity were most influential in driving enjoyment in playing mobile game MOBA genre.

\section{Appendix A. The questionnaire}

These items were measured using Likert scale from 1 "strongly disagree" to 6 "strongly agree" N=206

\begin{tabular}{|c|c|c|c|c|}
\hline No & Indicator & Mean & STD Dev & Source \\
\hline \multicolumn{5}{|c|}{ Challenge } \\
\hline 1 & Playing the game challenges me & 4.33 & 1.48 & \multirow{5}{*}{ [1] } \\
\hline 2 & Playing the game provide a good test of my playing skills & 4.14 & 1.46 & \\
\hline 3 & Playing the game challenges me to perform the best of my ability & 4.36 & 1.45 & \\
\hline 4 & Playing the game stretched my capabilities to the limits & 4.04 & 1.46 & \\
\hline 5 & Playing the games make me think & 4.19 & 1.56 & \\
\hline \multicolumn{5}{|c|}{ Variety } \\
\hline 1 & The game has variety of themes or landscapes & 4.19 & 1.45 & \multirow{3}{*}{ [1] } \\
\hline 2 & The game has a variety of visual or sound elements & 4.6 & 1.46 & \\
\hline 3 & The game has different themes in different level & 4.55 & 1.36 & \\
\hline \multicolumn{5}{|c|}{ Novelty } \\
\hline 1 & The game I most often play is surprising & 4.5 & 1.18 & \multirow{5}{*}{ [1] } \\
\hline 2 & The game I most often play is surprising & 4.05 & 1.38 & \\
\hline 3 & The game I most often play is innovative & 4.21 & 1.46 & \\
\hline 4 & The game I most often play is new & 3.4 & 1.66 & \\
\hline 5 & The game I most often play is fresh & 3.57 & 1.59 & \\
\hline \multicolumn{5}{|c|}{ Design Aesthetic } \\
\hline 1 & The screen design (colors, boxes, menus, etc) is attractive & 4.31 & 1.52 & \multirow{5}{*}{ [1] } \\
\hline 2 & The mobile game I most often play looks professionally designed & 4.56 & 1.49 & \\
\hline 3 & The game has good graphic design & 4.54 & 1.72 & \\
\hline 4 & The game has visually appealing overall look and feel & 5.52 & 1.63 & \\
\hline 5 & Overall, I find that the game looks attractive & 4.53 & 1.47 & \\
\hline \multicolumn{5}{|c|}{ Social Interaction } \\
\hline 1 & Playing the game enables me to make friends & 4.64 & 1.26 & \multirow{4}{*}{ [9] } \\
\hline 2 & I enjoy meeting the friends I made while playing game & 4.56 & 1.34 & \\
\hline 3 & Communicating with others is useful for playing game & 4.83 & 1.34 & \\
\hline 4 & Cooperating with others make playing more enjoyable & 5.01 & 1.13 & \\
\hline \multicolumn{5}{|c|}{ Perceived ease of use } \\
\hline 1 & Learning to use the game is easy for me & 4.56 & 1.28 & \multirow{3}{*}{ [1] } \\
\hline 2 & It is easy for me to perform the actions required to play the game & 5.08 & 0.95 & \\
\hline 3 & My interaction with the game is clear & 4.81 & 1.05 & \\
\hline
\end{tabular}




\begin{tabular}{|c|c|c|c|c|}
\hline 4 & I find the game easy to use & 4.7 & 1.28 & \\
\hline \multicolumn{5}{|c|}{ Interactivity } \\
\hline 1 & the game usually loads quickly & 4.13 & 1.24 & \multirow{3}{*}{ [1] } \\
\hline 2 & The game gives a fast response to my action & 4.3 & 1.27 & \\
\hline 3 & The game rapidly generates the information I need & 4.69 & 1.03 & \\
\hline \multicolumn{5}{|c|}{ Perceived Usefulness } \\
\hline 1 & For me this game has great value & 3.64 & 1.63 & \multirow{4}{*}{ [12], [14] } \\
\hline 2 & I find playing this game is useful & 3.87 & 1.56 & \\
\hline 3 & this game is an efficient tool for practice & 3.75 & 1.56 & \\
\hline 4 & I can get most of what I want from this game & 3.4 & 1.61 & \\
\hline \multicolumn{5}{|c|}{ Perceived Enjoyment } \\
\hline 1 & The mobile game I most often play is enjoyable & 4.28 & 1.34 & \multirow{4}{*}{ [1] } \\
\hline 2 & The mobile game I most often play is fun & 4.25 & 1.37 & \\
\hline 3 & The mobile game I most often play is entertaining & 4.39 & 1.27 & \\
\hline 4 & The mobile game I most often play is pleasant & 4.23 & 1.35 & \\
\hline \multicolumn{5}{|c|}{ Continuance Intention } \\
\hline 1 & I intend to continue playing the game rather than discontinue it's use & 3.52 & 1.63 & \multirow{4}{*}{ [1] } \\
\hline 2 & I will keep on playing the game in the future & 3.82 & 1.56 & \\
\hline 3 & I would continue playing the game & 3.78 & 1.62 & \\
\hline 4 & I believe I will continue playing the game & 3.67 & 1.64 & \\
\hline
\end{tabular}

\section{Appendix B Respondent Identity}

\begin{tabular}{|c|c|c|c|c|}
\hline No & Kelompok Responden & & Freq & $\%$ \\
\hline \multirow[t]{2}{*}{1} & Gender & Male & 190 & $92 \%$ \\
\hline & & Female & 16 & $8 \%$ \\
\hline \multirow[t]{5}{*}{2} & Age & $<15$ & 4 & $2 \%$ \\
\hline & & $15-19$ & 41 & $20 \%$ \\
\hline & & $20-24$ & 101 & $49 \%$ \\
\hline & & $25-29$ & 46 & $22 \%$ \\
\hline & & $>30$ & 14 & $7 \%$ \\
\hline \multirow[t]{3}{*}{3} & Device & Handphone & 179 & $87 \%$ \\
\hline & & Tablet & 24 & $12 \%$ \\
\hline & & Emulator & 15 & $7 \%$ \\
\hline \multirow[t]{3}{*}{4} & Play Intensity & Everyday & 135 & $66 \%$ \\
\hline & & $<3$ times a week & 32 & $16 \%$ \\
\hline & & 3-6 times a week & 39 & $19 \%$ \\
\hline \multirow[t]{4}{*}{5} & Experience playing Mobile games MOBA & $<6$ month & 7 & $3 \%$ \\
\hline & & 6 month- 1 year & 15 & $7 \%$ \\
\hline & & 1-2 year & 52 & $25 \%$ \\
\hline & & 2 years or more & 132 & $64 \%$ \\
\hline \multirow[t]{2}{*}{6} & Ever play AOV & Yes & 147 & $71 \%$ \\
\hline & & No & 59 & $29 \%$ \\
\hline \multirow[t]{2}{*}{7} & Ever play ML & Yes & 166 & $81 \%$ \\
\hline & & No & 40 & $19 \%$ \\
\hline \multirow[t]{2}{*}{8} & Ever play VG & Yes & 165 & $80 \%$ \\
\hline & & No & 41 & $20 \%$ \\
\hline
\end{tabular}


The $1^{\text {st }}$ International Conference on Business and Management of Technology (IConBMT)

August 3rd 2019, Institut Teknologi Sepuluh Nopember, Surabaya, Indonesia

\section{REFERENCES}

[1] J. Merikivi, V. Tuunainen, and D. Nguyen, "What makes continued mobile gaming enjoyable?," Comput. Human Behav., vol. 68, pp. 411-421, Mar. 2017.

[2] T. Wijman, "Mobile Revenues Account for More Than 50\% of the Global Games Market as It Reaches \$137.9 Billion in 2018," newzoo.com, 2018. [Online]. Available: https://newzoo.com/insights/articles/global-games-marketreaches-137-9-billion-in-2018-mobile-games-take-half/. [Accessed: 21-Feb-2019].

[3] B. Heere, "Embracing the sportification of society: Defining esports through a polymorphic view on sport," Sport Management Review, vol. 21, no. 1. Elsevier Ltd, pp. 21-24, 01Feb-2018.

[4] W. K. Pertiwi, "Menakar Potensi eSport di Indonesia," KOMPAS.com, 2017. [Online]. Available: https://tekno.kompas.com/read/2017/10/25/08490027/menakarpotensi-esport-di-indonesia. [Accessed: 23-Jul-2018].

[5] D. C. Funk, A. D. Pizzo, and B. J. Baker, "eSport management: Embracing eSport education and research opportunities," $J$. Sport Manag. Rev., pp. 7-13.

[6] S.-C. Wee and W.-W. Choong, "Gamification: Predicting the effectiveness of variety game design elements to intrinsically motivate users' energy conservation behaviour.," J. Environ. Manage., vol. 233, pp. 97-106, Mar. 2019.

[7] S. Deterding, R. Khaled, L. E. Nacke, and D. Dixon, "Gamification: Toward a Definition," in The ACM CHI Conference Proceedings, 2011.
[8] Y. S. Su, W. L. Chiang, C. T. James Lee, and H. C. Chang, "The effect of flow experience on player loyalty in mobile game application," Comput. Human Behav., vol. 63, no. C, pp. 240248, Oct. 2016.

[9] C. C. Chang, "Examining users' intention to continue using social network games: A flow experience perspective," Telemat. Informatics, vol. 30, no. 4, pp. 311-321, 2013.

[10] V. Mello and L. Perani, "Gameplay x playability: defining concepts, tracing differences," in SBC - Proceedings of SBGames 2012, 2012, pp. 157-164.

[11] J. Hamari, "Why do people buy virtual goods? Attitude toward virtual good purchases versus game enjoyment," Int. J. Inf. Manage., vol. 35, no. 3, pp. 299-308, 2015.

[12] A. Rese, S. Schreiber, and D. Baier, "Technology acceptance modeling of augmented reality at the point of sale: Can surveys be replaced by an analysis of online reviews?," J. Retail. Consum. Serv., vol. 21, no. 5, pp. 869-876, 2014.

[13] N. Z. Ismail, M. R. Razak, Z. Zakariah, N. Alias, and M. N. A Aziz, "E-Learning continuance intention among higher learning institution students' in Malaysia," Procedia - Soc. Behav. Sci., vol. 67, pp. 409-415, Dec. 2012.

[14] J. Pando-Garcia, I. Periañez-Cañadillas, and J. Charterina, "Business simulation games with and without supervision: An analysis based on the TAM model," J. Bus. Res., vol. 69, no. 5, pp. 1731-1736, May 2016. 